\title{
“VOCÊS CONHECEM ALGUMX ‘HETEROSSEXUAL FLEXÍVEL'?”:i MASCULINIDADES PERFORMATIVAS EM DEBATE
}

"DO YOU KNOW ANY 'FLEXIBLE STRAIGHT'?":
PERFORMATIVE MASCULINITIES IN DEBATE
"¿USTEDES CONOCEN ALGUNX 'HETEROSEXUAL FLEXIBLE'?":
MASCULINIDADES PERFORMATIVAS EN DEBATE
Dilton Ribeiro Couto Junior ${ }^{1}$, Leandro Teofilo de Brito ${ }^{2}$

\section{RESUMO}

A proposta do texto é investigar como o processo de constituição das masculinidades como enunciações performativas auxilia na formulação de críticas à masculinidade normativa. Para isso, analisamos duas conversas online realizadas no Facebook em 2015 com um grupo de jovens que não se identificam com a heterossexualidade e que vêm utilizando a referida rede digital como possibilidade de repensar os corpos, gêneros e sexualidades para além de modelos normativos binários. A pesquisa online foi desenvolvida por meio dos princípios da alteridade e do dialogismo de Mikhail Bakhtin, imprescindíveis para reconhecer pesquisador e sujeitos como atores sociais que buscam, coletivamente, novas formas de produzir conhecimento. O referencial teórico adotado para a análise das conversas é amparado, principalmente, pelas contribuições da teórica feminista Judith Butler, que compreende o gênero como performativo. Com base em seus estudos, reconhecemos a infinitude de sentidos possíveis atribuídos ao masculino e a necessidade de desestabilização dos essencialismos identitários. O material empírico produzido com os sujeitos evidenciou a denúncia de normas regulatórias de gênero que insistem em privilegiar determinadas formas de ser e de estar no mundo. Somado a isso, esse material trouxe a oportunidade para que pudéssemos tecer algumas breves reflexões para pensar uma educação subversiva à luz do pensamento queer. Isso implicou no desafio de reconhecermos a necessidade de expor, nos cotidianos escolares, os limites e fragilidades de uma masculinidade normativa que impede a capacidade humana de fabricar corpos, gêneros e sexualidades para além das heteronormas.

PALAVRAS-CHAVE: Sexualidade. Gênero. Performatividade. Masculinidade. Educação.

\begin{abstract}
The proposal of this text is to investigate how the constitution process of the masculinities as performative enunciations assists in formulating critiques to normative masculinity. In order to do this, we analyze two online conversations held on Facebook in 2015 with a group of young people who do not identify with heterosexuality and have been using the aforementioned digital network as a possibility to rethink bodies, genders and sexualities beyond binary normative models. The online research was developed through the principles of otherness and dialogism of Mikhail Bakhtin, essential to recognize researcher and subjects as social actors who seek, collectively, new ways to produce knowledge. The theoretical framework adopted for the analysis of the conversations is supported mainly by the contributions of Judith Butler, who understands gender as performative utterances. Based on her studies, we recognize the infinity of possible meanings attributed to the masculine and the need to destabilize identity essentialisms. The empirical material produced with the subjects showed the denunciation of regulatory norms of gender that insist on privileging certain forms of existence. Added to this, the material brought us the opportunity to briefly reflect upon a subversive
\end{abstract}

\footnotetext{
${ }^{1}$ Pós-doutorando em Educação da Universidade do Estado do Rio de Janeiro (ProPEd/UERJ) - Rio de Janeiro, RJ. Brasil. Doutorado em Educação - Universidade do Estado do Rio de Janeiro (UERJ) - Rio de Janeiro, RJ. Brasil. Docente - Fundação Centro de Ciências e Educação Superior à Distância do Estado do Rio de Janeiro (Fundação CECIERJ) - Rio de Janeiro, RJ. Brasil. E-mail: junnior 2003@yahoo.com.br

${ }^{2}$ Doutorando em Educação - Universidade do Estado do Rio de Janeiro (ProPEd/UERJ) - Rio de Janeiro, RJ. Brasil. Professor EBTT - Colégio Pedro II - Rio de Janeiro, RJ. Brasil. E-mail: teofilo.leandro@gmail.com Submetido em: 17/11/2016 - Aceito em: 12/06/2017
}

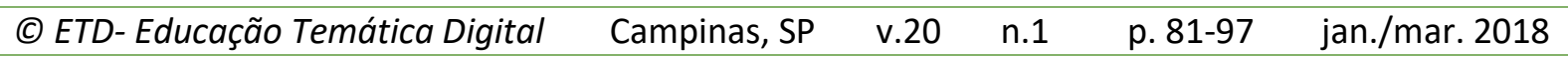


education in the light of queer theory. This implied the challenge of recognizing the need to expose, in schools' quotidian, the limits and fragilities of a normative masculinity that prevents the human capacity to produce bodies, genders and sexualities beyond hetero norms.

KEYWORDS: Sexuality. Gender. Performativity. Masculinity. Education.

\section{RESUMEN}

La propuesta de este texto es investigar como el proceso de constitución de las masculinidades como enunciaciones performativas auxilia en la formulación de críticas a la masculinidad normativa. Para eso analizamos dos conversaciones online realizadas en Facebook en 2015 con un grupo de jóvenes que no se identifican con la heterosexualidad y que vienen utilizando la referida red digital como posibilidad de repensar los cuerpos, géneros y sexualidades para más allá de los modelos normativos binarios. La investigación online se desarrolló a través de los principios de la alteridad y del dialogismo de Mijaíl Bajtín, imprescindibles para que se reconozcan el investigador y los sujetos como actores sociales que buscan, colectivamente, nuevas formas de producir conocimiento. El referencial teórico adoptado para el análisis de las conversaciones se ampara, principalmente, por las contribuciones de la teórica feminista Judith Butler, que comprende el género como performativo. Con base en sus estudios, reconocemos la infinitud de sentidos posibles atribuidos al masculino y a la necesidad de desestabilización del esencialismos identitarios. El material empírico producido con los sujetos evidenció la denuncia de normas regulatorias de género que insisten en privilegiar determinadas formas de ser y de estar en el mundo. Además, ese material trajo la oportunidad de que pudiéramos tejer algunas breves reflexiones para pensar una educación subversiva a la luz del pensamiento queer. Eso implicó en el desafío de reconocernos la necesidad de exponer, en los cotidianos escolares, los límites y fragilidades de una masculinidad normativa que impide la capacidad humana de fabricar cuerpos, géneros y sexualidades para más allá de las heteronormas.

PALABRAS CLAVE: Sexualidad. Género. Performatividad. Masculinidad. Educación.

\section{INTRODUÇÃO}

Nomear é uma questão política muito complexa e nomear através do gênero não é exceção. Giancarlo Cornejo

Corpos, gêneros e sexualidades vêm sendo classificados e indiciados, espacial e temporalmente, através da produção de saberes pelas inúmeras áreas do conhecimento. Essa necessidade de nomear o "que somos" (homem/mulher) por meio da identificação do nosso sexo (pênis/vulva) é colocada em manutenção e funcionamento por normas regulatórias de gênero sintonizadas com a ótica heteronormativa. Entretanto, o processo de nomeação dos corpos é atravessado por fatores que vão muito além da mera identificação do órgão genital do sujeito. Em função disso, defendemos com o trabalho a necessidade de ir na contramão de um pensamento heterocentrado que impõe regras sociais aparentemente naturais e incontestáveis ao fabricar modos de ser e de estar no mundo restritos a modelos normativos binários (macho/fêmea, homem/mulher, homo/heterossexual e ativo/passivo, para citar alguns). 
Cornejo (2015) nos auxilia a refletir sobre a nomeação dos corpos e a produção das masculinidades ao desenvolver um trabalho a partir de entrevistas concedidas por Italo, um sujeito que, durante as décadas de 1950 e 1960, viveu parte de sua infância em Lima, no Peru. Italo se dizia transgênero quando criança, característica que foi sendo ressignificada por ela na medida em que ia se descobrindo e colocando em xeque as expectativas sociais re(produzidas) pelas normas da coerência de gênero. De acordo com Cornejo, em 2007 Italo disse "que não é trans o bastante, pois não usa maquiagem ou vestido 'como uma mulher', e também não é suficientemente gay porque tem cabelo longo e generosos seios. Ela afirma [...] pode[r] se camuflar e se habituar a qualquer contexto" (p. 130, grifo nosso). Ao enfatizar a característica da camuflagem, reconhecemos a ênfase de Italo na construção social dos corpos, gêneros e sexualidades para além das heteronormas. Ao adotar a estratégias da camuflagem, ela vêm encontrando formas de resistência que denunciam a normatização da vida por meio da inserção dos corpos em categoriais sociais inteligíveis.

Cabe então questionar os limites e as fragilidades das masculinidades normativas, diante da compreensão do gênero como performativo. Butler (2015a) nomeia como performatividade de gênero a repetição e citação de enunciações linguísticas, atos, gestos e movimentos inscritos nos corpos dos sujeitos. Através da propagação e reiteração dos ideais do modelo da heterossexualidade reprodutora, a repetição e citação supracitadas buscam normatizar sexo, gênero e sexualidade. Entretanto, a filósofa estadunidense pontua também a possibilidade contingente nesta teorização, afirmando que a reiteração das normas não se processa de maneira plena, permitindo assim deslocamentos e desestabilizações de sentidos. Segundo a autora:

\footnotetext{
Os sujeitos são constituídos mediante normas que, quando repetidas, produzem e deslocam os termos por meio dos quais os sujeitos são reconhecidos. Essas condições normativas para a produção do sujeito produzem uma ontologia historicamente contingente [...]. Os esquemas normativos são interrompidos um pelo outro, emergem e desaparecem dependendo de operações mais amplas de poder, e com muita frequência se deparam com versões espectrais daquilo que alegam conhecer. (BUTLER, 2015b, p. 17).
}

A noção de performatividade de gênero caminha de encontro com as compreensões essencialistas sobre "sujeito" e "identidade" ao focalizar a forma com as quais os sujeitos constroem suas identificações por meio do uso da linguagem e do discurso. Neste contexto, sexo, gênero e sexualidade são efeitos e não causas de processos linguísticos-discursivos, o que acentua o caráter fictício e artificial destas categorias. É neste sentido que Judith Butler mostra como as identidades são performativas (SALIH, 2012).

Safatle (2015) afirma que as apropriações teóricas de Judith Butler são potentes para pensar não só discussões feministas em torno da desconstrução do gênero e da identidade. O autor expõe os limites de toda e qualquer identidade que seja caracterizada como universalizada e substancializada, tecendo assim importantes críticas ao uso político da 
noção de identidade social. Quanto ao gênero, sexualidade e a teorização sobre performatividade, respaldado pelos estudos de Butler, Safatle (2015) coloca ainda:

Identidades sexuais não deveriam ser pensadas como representações suportadas pela estrutura binária de sexos. Tratava-se, ao contrário, de tentar escapar da própria noção de representação através de uma teoria performativa do sexual. Teoria que sustenta a possibilidade de realização de atos subjetivos capazes de fragilizar o caráter reificado das normas, produzindo novos modos de gozo que subvertam as interdições postas pelo sistema binário de gêneros. (p.185-186).

Desenvolvendo essa discussão, trazemos em diálogo com a noção de performatividade a perspectiva queer (BUTLER, 2015a; SALIH, 2012; LOURO, 2008; SPARGO, 2006) para deslocar e desconstruir certa fixidez que é imposta nas identificações de gênero e sexualidade. A teoria queer questiona a heterossexualidade como norma e como um modelo compulsório a ser seguido e adotado pelos sujeitos, bem como o binarismo masculino/feminino presente nas identificações de gênero. Nesta premissa, aquelas e aqueles que não se conformam com o modelo heterocentrado para viver seus desejos argumentam que é necessário desestabilizar o sistema dicotômico e fixo de identidade de gênero e orientação sexual, dado como natural.

A política queer emergiu no contexto estadunidense na década de 1980, período em que os EUA viviam o preocupante alastramento da epidemia do hiv $^{3}$ e da aids (MISKOLCI, 2013). Além do sentido de "estranho" e/ou "ridículo", outra acepção ainda comumente empregada do termo queer, no contexto estadunidense, diz respeito a uma forma bastante pejorativa de se referir às pessoas homossexuais ("bicha", "sapatão", para citar algumas) (LOURO, 2008). Com toda sua carga de estranheza e marginalidade, a enunciação queer foi performatizada pelo movimento gay, durante esse período, com objetivo de oposição e contestação da rejeição que os homossexuais viviam com o hiv e a aids no país. Essa performatização ressignificou não apenas a expressão linguística do termo queer, como também afetou importante parcela do movimento gay, que passou então a ser denominado de LGBT. Nascia, neste contexto, não só o movimento queer como também os estudos queer.

Spargo (2006) afirma ser a teoria queer uma escola de pensamento abarcando um leque diverso de práticas, tais como análises das inter-relações de poder, saber e sexualidade, formulação de críticas ao sistema sexo-gênero, estudos sobre pessoas transgêneros, e a análise de textos literários, filmes, músicas, imagens, dentre outros meios midiáticos. Neste sentido, os estudos acadêmicos amparados pela fundamentação teórica

\footnotetext{
${ }^{3}$ Adotamos propositalmente o uso de letras minúsculas na escrita do termo aids "como recusa política de transformar a designação de uma doença, portanto um substantivo, em uma sigla cuja redação em maiúsculas colaborou para criar um pânico sexual" (MISKOLCI, 2014, p. 53).
} 
da perspectiva queer foram aos poucos se disseminando nas universidades, com ênfase sobre a necessidade de reiterar a construção social do gênero e da (heteros)sexualidade ${ }^{4}$. Salih (2012) complementa esse pensamento ao mostrar que "a teoria queer empreende uma investigação e uma desconstrução dessas categorias [sociais], afirmando a indeterminação e a instabilidade de todas as identidades sexuadas e 'generificadas'” (p. 20, grifo da autora).

Pensar as masculinidades pela noção de performatividade de gênero e pela perspectiva dos estudos queer implica reconhecer a desestabilização do essencialismo identitário e a infinitude de sentidos possíveis atribuídos ao masculino. Apostamos em incontáveis formas de produção das masculinidades nos processos de identificação dos sujeitos ao reconhecermos, neste artigo, as masculinidades como enunciações performativas. Conforme Rodrigues (2009) evidencia, "esse sonho da 'sexualidade sem número' quer ir além de classificações impostas, sem essencializar nem o masculino e nem o feminino" (p. 86). Isso significa uma aposta na potência das masculinidades performativas para expor e contestar normas regulatórias de gênero que insistem em normatizar e privilegiar determinadas formas de fabricação de corpos e gêneros.

A fundamentação teórica mencionada acima auxiliou no desenvolvimento das reflexões do presente texto, cujo objetivo é investigar como o processo de constituição das masculinidades como enunciações performativas auxilia na formulação de críticas à masculinidade normativa. Para isso, o nosso foco de análise neste trabalho foram duas conversas online realizadas no Facebook em 2015 com um grupo de jovens ${ }^{5}$ que não se identificam como heterossexuais e que vêm utilizando a referida rede digital como possibilidade de repensar os corpos, gêneros e sexualidades para além dos modelos binários e heteronormativos. Vale mencionar que adotamos o uso de pseudônimos, escolhidos pelos próprios participantes da pesquisa, para que os sujeitos não fossem identificados pelos seus nomes verdadeiros no texto.

A interação com o grupo de jovens internautas ocorreu por meio da construção de uma metodologia online de abordagem histórico-cultural. Essa abordagem compreende que pesquisador e sujeitos são reconhecidos como seres sociais e pertencentes a um dado momento histórico na dinâmica cultural. De acordo com Pereira (2015), "isso implica dizer que a História (e a história desse sujeito) não se inicia no ponto exato em que o sujeito

\footnotetext{
${ }^{4}$ Sobre a teoria queer e a repercussão dela no Brasil, ver os trabalhos de Louro $(2001,2008)$, Couto Junior (2016) e Pelúcio (2014, 2016).

${ }^{5} \mathrm{O}$ primeiro autor deste texto conduziu a pesquisa de campo no Facebook. As conversas online realizadas com os jovens são parte de seu trabalho de campo (iniciado em 2013 e finalizado em 2015) do doutorado. A pesquisa de doutorado focaliza o questionamento das normas regulatórias de gênero, propondo uma pedagogia inspirada na teoria queer para romper com as práticas sociais heteronormativas em contextos educacionais. O segundo autor deste trabalho auxiliou no desenvolvimento das reflexões aqui apresentadas, colaborando com a análise e interpretação dos dados empíricos produzidos no Facebook.

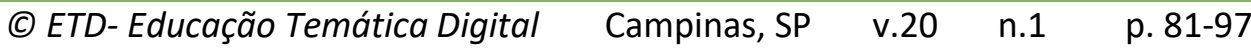
jan./mar. 2018
} 
nasce, mas que esse nascimento já é um acontecimento posicionado na história, na sociedade, na cultura" (p. 56) ${ }^{6}$. Segundo argumenta Recuero (2012), as práticas sociais contemporâneas vêm cada vez mais sendo mediadas pelos processos comunicacionais dos sites de redes sociais da internet. Em vista disso, vale reiterar o importante aspecto sociocultural do Facebook como uma das redes digitais mais populares atualmente no mundo e que vem sendo utilizada na produção colaborativa de novos conhecimentos pelos internautas (COUTO JUNIOR, 2013).

A metodologia de pesquisa online foi amparada pelos princípios da alteridade e do dialogismo de Mikhail Bakhtin, e reconhece que pesquisador e sujeitos são concebidos como produtores de linguagem e discursos, sempre inacabáveis. De acordo com Bakhtin (2011), as lembranças dos sujeitos (expressivos e falantes) são preenchidas pela capacidade humana de reinterpretar e reviver um dado momento na história, passível de ser reinventado através da rememoração. Nas palavras dele, "nas lembranças levamos em conta até os acontecimentos posteriores (no âmbito do passado), ou seja, percebemos e interpretamos o lembrado no contexto de um passado inacabado" (BAKHTIN, 2011, p. 399). Interagir com o outro no estudo de campo por meio de um olhar dialógico e alteritário permite reconhecer o encontro entre sujeitos como um acontecimento, em que o processo dialógico é uma forma "criativa e produtiva do eu se aproximar com suas palavras às palavras do outro, construindo uma compreensão que, por não ser de mero reconhecimento dos signos usados, é sempre uma proposta, uma oferta, uma resposta aberta a negociações" (GERALDI, 2013, p. 15) ${ }^{7}$. Dessa forma, as palavras enunciadas pelos jovens da pesquisa nos forneceram pistas imprescindíveis na tarefa de perceber o caráter performativo das masculinidades ao explicitarem a multiplicidade de formas de constituir-se sujeito para além dos modelos (hetero)normativos de ser e de estar no mundo.

A seguir, discutimos a categoria "heterossexual flexível" através da análise de uma conversa online que focalizou a produção de narrativas sobre masculinidades emergentes performatizadas na contemporaneidade. Posteriormente, analisamos outra conversa online que buscou questionar a nomeação dos corpos, gêneros e sexualidades através da desidentificação como estratégia em prol da necessidade de fazer proliferar multiplicidades de formas de constituir-se sujeito para além dos binômios macho/fêmea, homem/mulher, homo/heterossexual. Por fim, encerramos as reflexões do trabalho tecendo breves considerações sobre a necessidade de pensar uma educação subversiva à luz da perspectiva

\footnotetext{
${ }^{6}$ Nossa intenção aqui não é descrever com detalhes a emergência e a consolidação da abordagem históricocultural. Para outras informações sobre essa perspectiva teórica, ver as pesquisas de Freitas (2007, 2009, 2010), Ramos e Schapper (2010) e Couto Junior, Ferreira e Oswald (2017).

${ }^{7}$ Para uma discussão mais aprofundada sobre as implicações de se pesquisar em ambientes virtuais através dos princípios teórico-metodológicos bakhtinianos, ver os trabalhos de Macedo (2012) e Couto Junior e Oswald (2016).
}

n.1 p. $81-97$ jan./mar. 2018 
queer. Para isso, fomentamos críticas ao pensamento heterocentrado, expondo os limites e as fragilidades de uma masculinidade normativa circunscrita nos limites das (hetero)normas.

\section{MASCULINIDADES PERFORMATIVAS E A FLUIDEZ DAS IDENTIDADES SEXUAIS}

A conversa online abaixo foi iniciada no grupo do Facebook pelo desejo de Jorge de buscar maiores esclarecimentos sobre a categoria "heterossexual flexível". Por meio das perguntas lançadas por ele, "Vocês conhecem algumx 'heterossexual flexível'? Algum comentário sobre isso?", Jorge teve a oportunidade de discutir e analisar o caráter performativo das masculinidades e perceber o quanto as identidades sexuais também foram concebidas pelos sujeitos como sendo fluidas e em permanente transformação.

Jorge: Vocês conhecem algumx "heterossexual flexível"? Algum comentário sobre isso?

Polobio: Assim, acho muito arriscado e errado discutir a sexualidade de uma pessoa, já que você só pode classificar a sua própria sexualidade. Tendo dito isso, eu acredito que isso seja apenas um reflexo do machismo da sociedade, onde é menos pior você dizer que é héterossexual MAS, de vez em quando, você curte machos; do que você dizer com todas as letras que você gosta igualmente (ou não) de tudo.

JR Wilde: Conheço um hétero que já tentou me beijar algumas vezes, serve? Mas ele próprio não se define exatamente como hétero... Aparentemente é bissexual no finalzinho da escala, sabe, quase hétero mas que de vez em quando um homem rola. Quase nunca.

Thayane: É difícil um homem se definir flexível, ainda mais hetero flexível. Taí, eu queria entender pq homens "se definem" mais e mulheres tem maior tendência a se dizer bissexuais, mesmo que no fim das contas só namorem de fato homens ou mulheres. Acho que isso ainda é reflexo do machismo, até mesmo pros gays, que sofrem da mesma pressão que outros homens, de ter q se definir, ter q dar uma resposta concreta... não sei...

Jorge: eu tenho um grupo de amigos. alguns namoram mulheres, outros homens, outros não namoram. alguns se dizem heteros (principalmente os que namoram mulheres) e outros se dizem gays. até aí, nada de novo.

Certa vez, num reveillon, os gays estavam se pegando (o que é muito comum no nosso grupo) e os heteros decidiram que eles queriam se beijar. e todos se beijaram (ao mesmo tempo), sem deixar que nenhum homem gay participasse. Achei muito interessante isso, porque eles afirmaram interesse em conhecer uma sexualidade que eles não tinham experimentado, mas sem deixar um gay participar. eles diziam que só "heteros-flexíveis" poderiam participar. achei muito curioso!

Thayane: Gente, eu queria estar nessa festa com esses seus amigos! Que divertido!

Nogan: Existe machismo até entre os gays, e essa exigência por definição... você conversa com um gay e já vem a pergunta "Você é ativo, passivo ou versátil?" Acho que as pessoas tem necessidade de se classificar, acho que pode ser apenas um conforto para o ego "se encontrar". 
Quanto aos "hetero-flexiveis" acho bacana eles se comportarem assim num mundo cercado de machismo, e já vi machismo por parte dos gays que dizem "Ah! Ainda não saiu do armário completamente... ainda vai se descobrir"; Mas as vezes não, a pessoa está bem daquela forma, de vez ou outra, assim como uma mulher (que é mais bem aceita socialmente) experimentar o mesmo sexo, as vezes só na curiosidade de bêbado, as vezes por se sentir minimamente atraido, mas não quer entrar num relacionamento...

Só fico com medo até que ponto isso é real, ou só mais uma manobra de um cara homofóbico enrustido que vai ficar se gabando "Ah, só como uns viadinhos ai... como geral... blablabla"; Mas como cada um é cada um... não vou ficar julgando preciptadamente...

Patrick: Jorge, só faltou dizer que hoje eles deixam os gays beijarem eles na frente das namoradas. A maioria sabe lidar com isso na boa. Amo meus amigos héteroflexíveis, apesar de achar que o rótulo só dificulta ao invés de ajudar.

JR Wilde: Cara, já vi dos dois tipos. Às vezes pode ser manobra, outras vezes não. Há "hétero-flexíveis" e "hétero-flexíveis". Aliás, há pessoas e pessoas, né? xD Enfim, creio conhecer dos dois tipos, e ambos se consideram de alguma forma bi.

Justgia: Eu me considero homossexual, mas já beijei vááááááááááááários amigos homens. Os seus amigos, Jorge, se consideram hetero-flexíveis só por beijar homens?

Thayane: diminui um pouco esses ááá de vários, mas contemplei xD Justgia: Eu nem sei se foram tantos ááá, quis exagerar mesmo.

Jorge: Justgia, eu nunca conversei sobre isso com eles, a não ser em tons de brincadeira. vou investigar melhor!

Pesquisador: Nogan e Jorge, as pessoas têm necessidade mesmo da classificação! ajuda na organização e na autoidentificação... mas eu concordo com você, Patrick, a classificação acaba criando muitas confusões porque tendem encapsular o sujeito dentro de um MODELO. É difícil discutir gênero e sexualidade quando ficamos presos a modelos... por outro lado, eu acho ótimo as classificações, porque elas trazem muitas questões para serem pensadas, como vocês mesmo levantaram sobre aqueles que se dizem "hétero-flexíveis"! :D

A "flexibilidade" mencionada pelos sujeitos acima diz respeito aos limites e as fragilidades nas regulações das identidades sexuais e de gênero. Essa "flexibilidade" expõe o aspecto performativo das identificações e, mesmo com a imposição de práticas sociais (hetero)normativas recaindo sobre a valorização de uma identidade estável e fixa para os sujeitos, as falas dos participantes na conversa online argumentam em direção a deslocamentos identitários presentes nos diferentes contextos sociais. Neste sentido, Butler (2015b) coloca que "há condições normativas pelas quais os sujeitos são produzidos e que, em outro ponto no tempo, ocorrem 'rupturas' dessas condições" (p. 237). Por esse viés, a discussão empreendida pelos sujeitos no Facebook, ao focalizar a produção de narrativas sobre masculinidades emergentes performatizadas na contemporaneidade, evidenciou argumentos que apontam para desestabilizações nos modelos normativos do gênero. Essas masculinidades promovem rupturas nos sentidos mais estáveis do que se considera

$\begin{array}{llllll}\text { (C) ETD- Educação Temática Digital } & \text { Campinas, SP } & \text { v.20 } & \text { n.1 } & \text { p. 81-97 } & \text { jan./mar. } 2018\end{array}$


normativo para o masculino e, como afirma Louro (2008), "ainda que sejam tomadas todas as precauções, não há como impedir que alguns [sujeitos] se atrevam a subverter as normas" (p. 16).

De todo modo, as falas acima também apontam para repetições das (hetero)normas, mesmo em enunciações que discutiam deslocamentos de sentido sobre as masculinidades. Isso é o que Jorge mostra ao descrever que seus amigos que se identificam como heterossexuais buscam vivenciar experiências afetivas com outros homens que também autodenominam-se heterossexuais. Essa reiteração das (hetero)normas aparece na fala de Thayane, denunciando que os homens buscam se "definir" mais do que as mulheres, evitando associações que fujam do modelo da heterossexualidade. Já o participante Nogan vai além ao abordar a busca por certa fixidez identitária entre os sujeitos gays, quando os mesmos se classificam em ativos, passivos ou versáteis em suas relações amorosas.

Um aspecto bastante acentuado pelos participantes da conversa online foi a orientação sexual "bissexual". De certa forma essa orientação rompe com o binômio hetero/homossexual, mas cai na armadilha de comumente ser percebida pela referência da heteronorma. Em outras palavras, ser bissexual é ter que explicitar que, mesmo apresentando interesse em se relacionar afetivamente com o chamado "sexo oposto", o sujeito eventualmente também relaciona-se com pessoas do mesmo sexo, o que o deixa desprotegido perante as práticas homofóbicas. Para Zago (2014), isso ocorre porque a "heteronorma promete aos seus desviantes a proteção no seu seio desde que aceitem as regras que ela própria estabelece" (p. 152, grifos do autor). Dessa forma, em vez de o corpo e o sexo serem compreendidos pela capacidade do ser humano de reinventar a si próprio por meio da busca por diferentes prazeres e desejos corporais, as práticas sexuais acabam sendo enquadradas dentro de categoriais inteligíveis que, muitas vezes, desqualificam seus praticantes (WARNER, 1999). A normatização do sexo cria estratégias para separar as práticas consideradas "normais" das "anormais". Consequentemente, os sujeitos relegados ao campo da "anormalidade" "precisam ser controlados porque quaisquer escapes, rompimentos e movimentações que fizerem vão afetar diretamente a norma e os normais" (ZAGO, 2014, p. 145).

Segundo Butler (2015a), corpos, gêneros e sexualidades são atravessados por discursos que estabelecem limites normativos, suscitando amplas possibilidades de discussão sobre essas categorias. Neste sentido, a filósofa é elucidativa quando mostra que "tais limites se estabelecem sempre nos termos de um discurso cultural hegemônico, baseado em estruturas binárias que se apresentam como a linguagem da racionalidade universal" (p. 30-31). A autora prossegue afirmando que regimes de coerção são acionados com a intenção de fazer valer o pensamento hegemônico, responsável por reinscrever as normas regulatórias de gênero dentro de uma perspectiva de compreensão binária. 
Concordamos com a fala de Patrick, para quem "o rótulo só dificulta ao invés de ajudar". Essa crítica levantada pelo jovem diz respeito à criação de categoriais sexuais que buscam estabelecer padrões sociais a partir de critérios socialmente construídos. Entretanto, conforme defende Britzman (2010), "a sexualidade não segue as regras da cultura, mesmo quando a cultura tenta domesticar a sexualidade" (p. 89). O que é interessante perceber na conversa online com os participantes é o surgimento da categoria "flexível" de uma identidade sexual, necessária para dar visibilidade à forma como determinados sujeitos vêm vivenciando e experimentando certas relações afetivas com seus pares. Essa categoria coloca em xeque a masculinidade normativa e é potente para se pensar a transgressão das (hetero)normas.

\section{3 “NÃO SOMOS UM PONTO. SOMOS UM LEQUE": A NECESSIDADE DE FAZER PROLIFERAR MULTIPLICIDADES DE FORMAS DE CONSTITUIR-SE SUJEITO}

A segunda conversa online a seguir, também realizada no Facebook em 2015 entre o grupo de sujeitos participantes da pesquisa, foi desencadeada a partir de duas perguntas formuladas por Nogan: "Vim causar polêmica: Um virgem pode se considerar hétero/gay/bi sem ter praticado? Sentir desejo significa realmente ser?". O diálogo entre os jovens revelou os desafios de classificação das identidades sexuais a partir do que popularmente se denomina de "orientação sexual":

Nogan: Vim causar polêmica: Um virgem pode se considerar hétero/gay/bi sem ter praticado? Sentir desejo significa realmente ser?

JR Wilde: Pessoalmente, não precisei experimentar antes de saber dizer pelo que sentia atraído. Se este "sentir atraído" for minha orientação sexual, acho que ela pode ser definida a priori. E confirmada a posteriori. Aliás, acredito que orientação possa variar com o tempo, então tudo isso é meio complicado... Falo por experiência pessoal. Geralmente sou bem pouco sensível a mulheres, mas há uns períodos... diferentes. Não sei explicar. E tbm não é toda mulher que desperta, aliás. Enfim. Não acho que sexualidade seja tão bem definida assim. Por mais que pegue a definição "objeto de desejo", acredito que a intensidade e msm o objeto de desejo possa variar (não com uma plasticidade infinita, dentro de limites pessoais), de acordo com outras circunstâncias.

Nogan: cada vez me sinto mais confortável em derrubar essas polaridades gay-bihetero porque leio sobre cada caso e fico tentando "encaixar", como se fosse essa a lei que definisse a sexualidade. JR Wilde, esse negócio de sexualidade mudando ao longo do tempo, acho complicado, mas compreendo o que é isso. Por hora, estou num relacionamento e sinto minha bissexualidade latente, mas quando estava solteiro, sentia que podia procurar 'qualquer' pessoa que me atraisse, fosse homem ou mulher. E eu me envolvo (para ter relacionamentos minimamente fixos) muito mais com emocional do que com o fisico. (Eu era apaixonado durante o período do colégio todo pela minha amiga, que trocava confidencias, mas nunca fiz nada porque achava que se eu tinha atração por homens, eu deveria ser gay, hoje já não tenho certeza de nada, mas estou bem com isso). 
Jorge: muito complexo. próxima pergunta! brincadeira. acho que é tudo muito fluido, quando se pensa em sexualidade. Invoca pensar em definições do "que é ser gay", "o que é ser hetero". é tudo muito mais plural e depende das variáveis. Mas posso dizer da minha experiência pessoal: eu perdi a virgindade aos 17 anos $e$ muito antes disso já me considerava gay. Logo depois de perder a virgindade le foi com um homem), comecei a namorar uma garota (logo depois mesmo, tipo... no dia seguinte hehe). e aí? e se eu ainda estivesse com ela? ainda seria gay? Tô colocando isso porque não acho que tenha uma resposta simples de sim ou não para a sua pergunta, Nogan. talvez precisemos embarcar num trem e caminhar um pouco por diferenças e possibilidades. E, quem sabe, sim-e-não estejam divididos por uma linha que nós colocamos entre eles.

Nogan: Sim, o que quero dizer é que essas definições "hetero"/"gay" são tão arbitrárias que as vezes não correspondem a realidade... e ai, mesmo eu não "sabendo" o que sou, tento me definir. Outro dia vi uma escala, que variava desde o Hetero até o Gay, e exatamente no meio colocava o Bi. Cada um estaria em um ponto desta escala. Hoje já penso que cada pessoa, na verdade, tem uma faixa dentro dessa escala, que varia por fatores que não compreendemos (completamente), e poderia criar um hetero-flexivel e um gay com tendencias bi... ou mesmo alguém que compreende todo o espectro da sexualidade, um panssexual, ou nenhum, um assexual. Não somos um ponto. Somos um leque. VRÁÁ

Para Butler (2010), embora os discursos sociais em torno das "categorias de identidade [sexual e de gênero] tendam a cultivar identificações a serviço de um objetivo político, pode ocorrer que a persistência da desidentificação seja igualmente crucial para a rearticulação da contestação democrática" (p. 156, grifo da autora). Com isso em mente, acreditamos que a desidentificação se constitua uma estratégia potente para desestabilizar formas normativas de construção das masculinidades. Isso é o que defendem os sujeitos da pesquisa ao acreditarem que há a necessidade de fazer proliferar multiplicidades de formas de constituir-se humano para além das heteronormas e para além das formas preconcebidas de compreensão dos gêneros e sexualidades. Nogan caminha nessa direção e concorda que "cada vez me sinto mais confortável em derrubar essas polaridades gay-bihetero porque leio sobre cada caso e fico tentando 'encaixar', como se fosse essa a lei que definisse a sexualidade". De acordo com Zago (2014), "os corpos, os sexos, os gêneros e as sexualidades não são algo que nós temos, nem algo que nós detemos ou que nós guardamos encerrados em nós mesmos, mas sim algo que exercemos continuamente e que materializamos como ideal regulatório" (p. 149). Dessa forma, os discursos sociais (re)produzidos pelas (hetero)normas vêm alimentando a naturalização da relação monogâmica heterossexual com fins reprodutivos em detrimento de outras estéticas de existência como aquelas compreendidas pelas "polaridades gay-bi-hetero" mencionadas por Nogan. Nesta premissa, Butler (2015a) levanta que as normas inteligíveis de coerência e continuidade se fazem presentes na noção de identidade social por leis culturais que legitimam, estabelecem e regulam formas e significados para a sexualidade, porém, mostram-se igualmente produtivas do ponto de vista de problematização e denúncia do discurso generificado e heterocentrado: 
Ora, do ponto de vista desse campo, certos tipos de "identidade de gênero" parecem ser meras falhas do desenvolvimento ou impossibilidades lógicas, precisamente por não se conformarem às normas da inteligibilidade cultural. Entretanto, sua persistência e proliferação criam oportunidades críticas de expor os limites e os objetivos reguladores desse campo de inteligibilidade e, consequentemente, de disseminar, os próprios termos dessa matriz de inteligibilidade, matrizes rivais e subversivas de desordem do gênero. (p. 44).

Roseiro, Fim e Rodrigues (2016) elucidam que "nem todas as palavras são bemvindas aos corpos, que palavras podem não dizer de um corpo por imposição, por uma 'vontade' de não as deixarem dizer. 'Silêncio!', berra o corpo para aquelas palavras"' (p. 34). Em função do aprisionamento dos corpos por determinadas palavras, os sujeitos na conversa acima também berram seus muitos "Silêncio!". As palavras de Jorge revelam que seria preciso questionar as "definições do 'que é ser gay', 'o que é ser hetero'” com a intenção de provocar desestabilizações nas normas regulatórias de gênero que produzem as experiências da abjeção. Além disso, Britzman (1996) mostra que os "próprios significantes 'gay' e 'lésbica' devem ser rearticulados de forma que sejam prazerosos, interessantes e eróticos" (p. 83), propiciando que questionemos a produção dos estigmas sociais atribuídos às pessoas que fogem à matriz heterossexual.

\section{POR UMA EDUCAÇÃO SUBVERSIVA À LUZ DO PENSAMENTO QUEER: PALAVRAS FINAIS}

A partir das reflexões tecidas anteriormente, pretendemos realizar breves considerações sobre a necessidade de pensar uma educação subversiva à luz do pensamento queer ${ }^{8}$. Além de pesquisadores, o nosso lugar de fala é impregnado também pelas nossas experiências de docência em instituições da Educação Básica na cidade do Rio de Janeiro. Discutir masculinidades performativas neste texto deve-se à nossa constante preocupação pela forma como corpos, gêneros e sexualidades são atravessados por normas regulatórias alimentadas, comumente, por práticas sociais heteronormativas colocadas em funcionamento e manutenção por estudantes e seus professores.

A relação dialógica com os jovens no Facebook propiciou a promoção de reflexões que revelam o nosso desejo por novas formas de pensar a produção de conhecimento para o campo de estudos de gênero e sexualidade. Caminhamos com o pensamento de VeigaNeto (2014), que propõe: "se quisermos um mundo melhor, teremos de inventá-lo, já sabendo que conforme vamos nos deslocando para ele, ele vai mudando de lugar. À medida que nos movemos para o horizonte, novos horizontes vão surgindo, num processo infinito" (p. 26). Dessa forma, os saberes debatidos com os sujeitos nos alertaram também para a

\footnotetext{
${ }^{8}$ Neste contexto, vale mencionar outros trabalhos que, antenados com as questões educacionais, se inspiram na teoria queer para propor a "educação rizomática" (BORBA; LIMA, 2014), a "pedagogia queer" (COUTO JUNIOR, 2016; CORNEJO, 2015; CÉSAR, 2012) e o “embichamento do currículo" (SUSSEKIND; REIS, 2015).
} 
urgência de planejarmos estratégias educacionais através de ações voltadas para o enfrentamento da heteronormatividade. Não há caminhos pré-determinados para esse planejamento; há, sim, a necessidade de realizá-lo diante das circunstâncias sociais apresentadas por cada cotidiano escolar.

A percepção dos corpos e gêneros em categoriais estáticas e binárias é comumente evidenciada em cotidianos educacionais através do uso de discursos que regulam aquilo que é hegemonicamente considerado direcionado "para meninos" e, consequentemente, "para meninas" (BRITO, 2015). Entendendo que a transgressão constitui-se na capacidade humana de resistir às normas e regulações sociais (ZAGO, 2014), cabe questionarmos como seria possível transgredir as mesmas normas que nos formam e que tentam, incessantemente, nos moldar à luz de uma organização social majoritariamente calcada na divisão binária do mundo pelo órgão sexual (pênis $\leftrightarrow$ homem $\leftrightarrow$ masculino / vulva $\leftrightarrow$ mulher $\leftrightarrow$ feminino).

As experiências da abjeção são marcadas pela produção de uma diferença desqualificante, cuja premissa baseia-se na ideia de que há uma referência, um padrão a ser seguido. De acordo com Roseiro, Fim e Rodrigues (2016), "o politicamente correto assusta porque ele diz de uma 'maioria', diz de uma 'vontade de todos'. E nos perguntamos: quão submissa, regrada e vazia de vida pode ser uma 'vontade de todos'?" (p. 41). Ainda que essa "vontade de todos" exerça coercitivamente forças regulatórias que insistam em governar os corpos, Zago (2014) chama a atenção para o que ele denomina de "curvas-de-normalidade" para evidenciar a existência de "zonas de escape" "normalmente situadas nos dois extremos das curvas" (p. 144). Isso significa que há a possibilidade de questionarmos os padrões sociais (re)produzidos por uma "maioria", colocando em questionamento o poder de uma norma que, pautada pela lógica da referência, inferioriza todos aqueles que se recusam a viver sob determinados princípios.

Diante do exposto, defendemos uma educação subversiva que possa fomentar críticas capazes de expor os limites e as fragilidades de uma masculinidade normativa que limita a capacidade humana de fabricar corpos, gêneros e sexualidades. Almejamos também que as normas regulatórias de gênero sejam trabalhadas no sentido de denunciar a força com que os discursos machistas e homofóbicos inserem determinados grupos de sujeitos na condição de seres abjetos. Consequentemente, essa educação inspirada na teoria queer seria convidativa à percepção sobre como os gêneros e as sexualidades são construções socioculturais; como construtos sociais, isso significa que gêneros e sexualidades são produzidos num determinado tempo e espaço, o que implica a ideia de que estão em constantemente processo de disputa social, política e ideológica. Seguimos acreditando que uma educação subversiva requer "desaprender aquilo que aprendemos historicamente a ser para vislumbrar o que podemos nos tornar" (BORBA; LIMA, 2014, p. 12). Indo ao encontro dessa perspectiva, que possamos enfraquecer a normatização do modelo heterossexual nos

$\begin{array}{llllll}\text { (C) ETD-Educação Temática Digital } & \text { Campinas, SP } & \text { v.20 } & \text { n.1 } & \text { p. 81-97 } & \text { jan./mar. } 2018\end{array}$


cotidianos escolares ao performatizarmos nossos gêneros em prol da multiplicidade de formas de nos constituirmos seres humanos.

\section{REFERÊNCIAS}

BAKHTIN, Mikhail. Estética da criação verbal. Tradução de Paulo Bezerra. 6. ed. São Paulo: Martins Fontes, 2011. 478 p. ISBN 978-85-7827-470-2.

BORBA, Rodrigo; LIMA, Fátima. Por uma educação rizomática: sobre as potências queer, a política menor e as multiplicidades. Revista Periódicus, Salvador, v. 1, n. 2, p. 1-14, 2014. Disponível em:

http://www.portalseer.ufba.br/index.php/revistaperiodicus/article/view/12885/9198 . Acesso em: 20 mar. 2015.

BRITO, Leandro Teófilo de. Gênero no espaço escolar: normatizações e deslocamentos cotidianos. Caderno Espaço Feminino, Uberlândia, v. 28, n. 1, p. 72-89, jan./jun. 2015. Disponível em: http://www.seer.ufu.br/index.php/neguem/article/view/29708 . Acesso em: 10 maio 2016.

BRITZMAN, Deborah. O que é esta coisa chamada amor: identidade homossexual, educação e currículo. Revista Educação \& Realidade, Porto Alegre, v. 21, n. 1, p. 71-96, jan./jun. 1996.

BRITZMAN, Deborah. Curiosidade, sexualidade e currículo. In: LOURO, Guacira Lopes (Org.). O corpo educado: pedagogias da sexualidade. 3. ed. Belo Horizonte: Autêntica, 2010. 176 p. ISBN 978-85-86583-33-9.

BUTLER, Judith. Corpos que pesam: sobre os limites discursivos do "sexo". In: LOURO, Guacira Lopes (Org.). 0 corpo educado: pedagogias da sexualidade. 3. ed. Belo Horizonte: Autêntica, 2010. 176 p. ISBN 978-85-86583-33-9.

BUTLER, Judith. Problemas de gênero: feminismo e subversão da identidade. Tradução de Renato Aguiar. 8. ed. Rio de Janeiro: Civilização Brasileira, 2015a. 286 p. ISBN 978-85-2000611-5.

BUTLER, Judith. Quadros de guerra: quando a vida é passível de luto. Rio de Janeiro: Civilização Brasileira, 2015b. 288 p. ISBN 978-85-200-0965-9.

CÉSAR, Maria Rita de Assis. A diferença no currículo ou intervenções para uma pedagogia queer. Educação Temática Digital, Campinas, v. 14, n. 1, p. 351-362, jan./jun. 2012. Disponível em: http://periodicos.sbu.unicamp.br/ojs/index.php/etd/article/view/1257 . Acesso em: 5 ago. 2013.

CORNEJO, Giancarlo. Por uma pedagogia queer da amizade. Áskesis, São Carlos, v. 4, n. 1, p. 130-142, jan./jun. 2015. Disponível em:

http://www.revistaaskesis.ufscar.br/index.php/askesis/article/view/47 . Acesso em: 5 abr. 2016. 
COUTO JUNIOR, Dilton Ribeiro. Cibercultura, juventude e alteridade: aprendendoensinando com o outro no Facebook. Jundiaí: Paco Editorial, 2013. 164 p. ISBN 978-85-8148180-7.

COUTO JUNIOR, Dilton Ribeiro. Gênero, sexualidade e a teoria queer na educação: colocando em questão a heteronormatividade. Atos de Pesquisa em Educação, Blumenau, v. 11, n. 1, p. 250-270, jan./abr. 2016. Disponível em:

http://proxy.furb.br/ojs/index.php/atosdepesquisa/article/view/4782 . Acesso em: 16 ago. 2015.

COUTO JUNIOR, Dilton Ribeiro; FERREIRA, Helenice Mirabelli Cassino; OSWALD, Maria Luiza Magalhães Bastos. Compartilhando experiências sobre o "armário": as conversas online como procedimento metodológico da pesquisa histórico-cultural na cibercultura. Revista Interface Científica - Educação, Aracaju, v. 6, n. 1, p. 23-34, out. 2017. Disponível em: https://periodicos.set.edu.br/index.php/educacao/article/view/4423/2415. Acesso em: 26 out. 2017.

COUTO JUNIOR, Dilton Ribeiro; OSWALD, Maria Luiza Magalhães Bastos. "Tudo o que você disser vira pesquisa": trilhando caminhos teórico-metodológicos na pesquisa com internautas. Revista Teias, Rio de Janeiro, v. 17, p. 179-193, 2016. Disponível em: http://www.e-publicacoes.uerj.br/index.php/revistateias/article/view/24821/18083 . Acesso em: 15 out. 2016.

FREITAS, Maria Teresa de Assunção. A pesquisa qualitativa de abordagem histórico-cultural: fundamentos e estratégias metodológicas. REUNIÃO ANUAL DA ASSOCIAÇÃO NACIONAL DE PÓS- GRADUAÇÃO E PESQUISA EM EDUCAÇÃO, 30., 2007, Caxambu. Anais... Caxambu: Espaço Livre, 2007, 16p. Disponível em:

http://30reuniao.anped.org.br/minicursos/ementa\%20do\%20minicurso\%20do\%20gt20\%20. pdf . Acesso em: 17 jan. 2009.

FREITAS, Maria Teresa de Assunção. A pesquisa de abordagem histórico-cultural: um espaço educativo de constituição de sujeitos. Revista Teias, Rio de Janeiro, v. 10, n. 19, p. 1-12, 2009. Disponível em: http://www.e-publicacoes.uerj.br/index.php/revistateias/article/view/24057/17026 . Acesso em: 10 set. 2016.

FREITAS, Maria Teresa de Assunção. Discutindo sentidos da palavra intervenção na pesquisa de abordagem histórico-cultural. In: FREITAS, Maria Teresa de Assunção; RAMOS, Bruna Sola (Org.). Fazer pesquisa na abordagem histórico-cultural: metodologias em construção. Juiz de Fora: Ed. UFJF, 2010. 196 p. ISBN 978-85-7672-092-8.

GERALDI, João Wanderley. Bakhtin tudo ou nada diz aos educadores: os educadores podem dizer muito com Bakhtin. In: FREITAS, Maria Teresa de Assunção (Org.). Educação, arte e vida em Bakhtin. Belo Horizonte: Autêntica, 2013. 112 p. ISBN 978-85-8217-123-3. 
LOURO, Guacira Lopes. Teoria queer - uma política pós-identitária para a educação. Revista Estudos Feministas, Florianópolis, v. 9, n. 2, p. 541-553, 2001. Disponível em: http://www.scielo.br/pdf/ref/v9n2/8639.pdf . Acesso em: 12 jun. 2012.

LOURO, Guacira Lopes. Um corpo estranho: ensaios sobre sexualidade e teoria queer. Belo Horizonte: Autêntica, 2008. 96 p. ISBN 978-85-7526-116-3.

MACEDO, Nélia Mara Rezende. Crianças e redes sociais: uma proposta de pesquisa online. REUNIÃO ANUAL DA ASSOCIAÇÃO NACIONAL DE PÓS-GRADUAÇÃO E PESQUISA EM EDUCAÇÃO, 35., 2012, Anais... Porto de Galinhas. Educação, cultura, pesquisa e projetos de desenvolvimento: o Brasil do século XXI, 2012, 17p. Disponível em: http://35reuniao.anped.org.br/images/stories/trabalhos/GT16\%20Trabalhos/GT162101 int.pdf . Acesso em: 6 jul. 2014.

MISKOLCI, Richard. Teoria queer: um aprendizado pelas diferenças. Belo Horizonte: Autêntica, 2013. 88 p. ISBN 978-85-65381-28-4.

MISKOLCl, Richard. Um saber insurgente ao sul do Equador. Revista Periódicus, Salvador, v. 1, n. 1, p. 43- 67, maio/out. 2014. Disponível em: https://portalseer.ufba.br/index.php/revistaperiodicus/article/view/10148/7252 . Acesso em: 21 maio 2015.

PELÚCIO, Larissa. Breve história afetiva de uma teoria deslocada. Revista Florestan, São Carlos, ano 1, n. 2, p. 26-45, nov. 2014. Disponível em:

http://www.revistaflorestan.ufscar.br/index.php/Florestan/article/view/63 . Acesso em: 18 mar. 2015.

PELÚCIO, Larissa. O cu (de) Preciado - estratégias cucarachas para não higienizar o queer no Brasil. Iberic@I: Revue D'études Ibériques et Ibéro-américaines, Paris, n. 9, p. 123-136, printemps 2016. Disponível em: http://iberical.paris-sorbonne.fr/wpcontent/uploads/2016/05/Pages-from-Iberic@l-no9-printemps-2016-12.pdf..Acesso em: 10 ago. 2016.

PEREIRA, Rita Marisa Ribes. Por uma ética da responsividade: exposição de princípios para a pesquisa com crianças. Currículo Sem Fronteiras, v. 15, n. 1, p. 50-64, jan./abr. 2015. Disponível em: http://www.curriculosemfronteiras.org/vol15iss1articles/pereira.pdf . Acesso em: 11 fev. 2016.

RAMOS, Bruna Sola; SCHAPPER, Ilka. (Des)atando os nós da pesquisa na abordagem histórico-cultural. In: FREITAS, Maria Teresa de Assunção; RAMOS, Bruna Sola (Org.). Fazer pesquisa na abordagem histórico-cultural: metodologias em construção. Juiz de Fora: Ed. UFJF, 2010. 196 p. ISBN 978-85-7672-092-8.

RECUERO, Raquel. A conversação em rede: comunicação mediada pelo computador e redes sociais na internet. Porto Alegre: Sulina, 2012. 238 p. ISBN 978-85-205-0650-9.

RODRIGUES, Carla. Coreografias do feminino. Florianópolis: Mulheres, 2009. 136 p. ISBN 978-85-86501-83-8. 
ROSEIRO, Steferson Zanoni; FIM, Matheus Magno dos Santos; RODRIGUES, Alexsandro. Dosagens do imoral, overdose de bichice. In: RODRIGUES, Alexsandro; MONZELI, Gustavo; FERREIRA, Sérgio Rodrigo da Silva (Org.). A política no corpo: gêneros e sexualidades em disputa. Vitória: EDUFES, 2016. 346 p. ISBN 978-85-7772-332-4.

SAFATLE, Vladimir. Posfácio. Dos problemas de gênero a uma teoria da despossessão necessária: ética, política e reconhecimento em Judith Butler. In: BUTLER, Judith. Relatar a si mesmo: crítica da violência ética. Belo Horizonte: Autêntica, 2015. 200 p. ISBN 978-85-8217688-7.

SALIH, Sarah. Judith Butler e a teoria queer. Tradução de Guacira Lopes Louro. Belo Horizonte: Autêntica, 2012. 240 p. ISBN 978-85-65381-38-3.

SPARGO, Tamsin. Foucault e a teoria queer. Tradução de Wladimir Freire. Rio de Janeiro: Pazulin; Juiz de Fora: Ed. UFJF, 2006. 72 p. ISBN 978-85-7672-037-9.

SUSSEKIND, Maria Luiza; REIS, Graça Franco da Silva. Currículos-como-experiências-vividas: um relato de embichamento nos cotidianos de uma escola na cidade do Rio de Janeiro. Currículo Sem Fronteiras, v. 15, n. 3, p. 614-625, set./dez. 2015. Disponível em: http://www.curriculosemfronteiras.org/vol15iss3articles/sussekind-reis.pdf . Acesso em: 23 maio 2016.

VEIGA-NETO, Alfredo. Foucault \& a educação. 3.ed. Belo Horizonte: Autêntica, 2014. 160 p. ISBN 978-85-7526-105-7.

WARNER, Michael. The trouble with normal: sex, politics, and the ethics of queer life. Massachusetts: Harvard Univ. Press, 1999. 230 p. ISBN 0-674-00441-8.

ZAGO, Luiz Felipe. Quando a norma range os dentes - corpo, norma e transgressão. Textura, Canoas, n. 31, p. 140-155, maio/ago. 2014. Disponível em:

http://www.periodicos.ulbra.br/index.php/txra/article/view/1209 . Acesso em: 20 ago. 2015.

\footnotetext{
i Revisão gramatical do texto sob a responsabilidade de Leonardo Barros Medeiros - Doutorando em Literaturas de Língua Portuguesa pela Universidade de Coimbra. E-mail: leonardoletras@gmail.com
} 